\title{
Spectrophotometric Determination of Trace Amount of Nitrite in Water with p-Nitroaniline and 1-Naphthol
}

\author{
Deba Bahadur Khadka' ${ }^{1}$ and Laxmi Pachhai ${ }^{2}$ \\ ${ }^{1}$ Central Department of Chemistry, T.U., Kirtipur, Kathmandu, Nepal \\ ${ }^{2}$ Department of Chemistry, Tri-Chandra Multiple Campus, T.U., Kathmandu, Nepal \\ E-mail:khadkadeba@yahoo.com
}

\begin{abstract}
A simple, selective and sensitive method for the spectrophotometric determination of nitrite in different natural and waste water samples is applied. Nitrite reacts with p-nitroaniline in the presence of hydrochloric acid to form diazonium cation which is subsequently coupled with 1-naphthol to form a stable azo dye. The $\lambda_{\max }$ for the azo dye is found to be $610 \mathrm{~nm}$. At analytical wavelength $610 \mathrm{~nm}$ the Lambert-Beer's law obeys over the concentration range $0.035-0.123$ $\mu \mathrm{g} / \mathrm{ml}$ of nitrite. The correlation coefficient, molar absorptivity and Sandell's sensitivity of the method were found to be $0.99,5.24 \times 10^{4}$ lit. $\mathrm{mol}^{-1} \mathrm{~cm}^{-1}$ and $8.77 \times 10^{-4} \mu \mathrm{g} \mathrm{cm}^{-2}$ respectively. The percentage recovery was found to range from $93-109 \%$ and the interference of foreign ions was also studied.
\end{abstract}

Keywords: p-Nitroaniline, 1-naphthol, spectrophotometric, molar absorptivity, nitrite

\section{INTRODUCTION}

Nitrite has been considered as a potentially hazardous compound for human health. Trace amount of nitrite in drinking water may to causes mathemoglobinemia, in infants and with long term exposure is possible cancer risk. In potable water occurrence of nitrite is objectionable as it causes methemoglobinemia and anorexia (Calabrese, 1963). The maximum admissible concentration (MAC) is $0.1 \mathrm{mg} / \mathrm{l}$ and the U.S Public Health Association specific $0.06 \mathrm{ppm}$ as the maximum permissible limit of nitrite in potable water (SMEWSIW, 1976; Chaurasis \& Verma, 1994).

As nitrite shows potential toxicity and harmful effects by forming carcinogenic nitrosoamines, the determination of nitrite is important in environmental protection and public health. Therefore, several methods for nitrite determination have been developed in recent years, such as kinetic method, chromatography, potentiometry, amperometry, polarography, capillary electrophoresis, and spectrophotometry and flow injection analysis (FIA) systems (Butt et al. 2001; Siu \& Henshall, 1998). Some of these methods have the disadvantage of the employment of large volume of toxic reagents, low sample frequency, application of complicated flow injection systems, poor reproducibility, expensive and time consuming separation procedures and, for certain method, the requirement of high temperature. Researchers developed the methods based on reaction other than Griess reaction has also been developed for nitrite determination. But, in spite of their sensitivity, they suffer from drawback such as tedious synthesis of the reagent and relatively long reaction time.

For the determination of nitrite following diazotization and coupling reaction is proposed to new reagent system. Nitrite reacts with PNA to form a diazonium cation which is subsequently coupled with 1- naphthol to form a violet dye. Thus the objective of the present study is to apply the develop method for the determination of nitrite in the different natural and waste water samples.

\section{MATERIALS AND METHODS}

In this study, a SP meterteke 870 spectrophotometer of Thailand with $1.0 \mathrm{~cm}$ matched glass cells were used for absorbance measurements.

All chemicals used were of analytical grade and double distilled water was used for the dilution of reagents and samples. A stock nitrite solution was prepared by dissolving $0.375 \mathrm{~g}$ of dried sodium nitrite in distilled water and dilute to $250 \mathrm{ml}$, a pellet of sodium hydroxide and about $1 \mathrm{ml}$ of chloroform were added to prevent the liberation of nitrous acid and to inhibit the bacterial growth respectively. The working solutions were prepared by appropriate dilution of each stock solution with double distilled water. p-nitroaniline (PNA) solution of $1 \times 10^{-3} \mathrm{M}$ was prepared in $20 \%$ aqueous ethanol up to $100 \mathrm{ml} .0 .1 \%$ of 1-naphthol solution was prepared by dissolving $0.1 \mathrm{gm}$ of the reagents in $100 \mathrm{ml}$ of $1.2 \mathrm{M}$ sodium hydroxide up to mark.

\section{RESULTS AND DISCUSSION}

Spectral Studies for the Determination of $\lambda_{\text {max }}$

Fig. 1 shows the absorption spectrum of the azo dye formed in alkaline medium with $10 \mu \mathrm{g} / \mathrm{ml}$ of nitrite is treated according to the recommended procedure 
using 1-naphthol as a coupling reagent. The maximum absorption i.e $\lambda_{\max }$ occurs at $610 \mathrm{~nm}$.

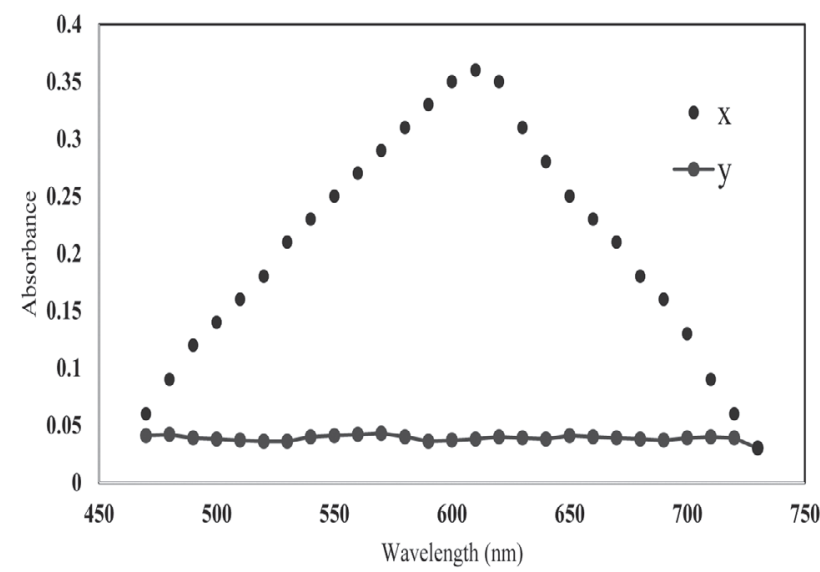

Fig. 1. X-Absorption Spectra of Azo dye Measured

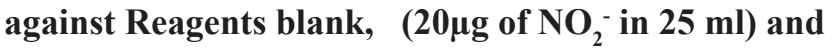
Y- Reagents blank against water.

\section{Effect of p-Nitroaniline Concentration}

To determine the optimum concentration of p-nitroaniline on the colour intensity, the concentration of PNA was varied from $0.00028 \%$ to $0.00224 \%$ in final solution. For this experiment, the $0.014 \%$ PNA solution was used. The colour development was then completed according to recommended procedure and plot of absorbance versus concentration of PNA solution for $10 \mu \mathrm{g} / \mathrm{ml}$ of nitrite is shown in Fig. 2. The curve shows that concentration lower than $0.00112 \%$ did not yield satisfactory results and absorption depends upon concentration of PNA. Above $0.00112 \%$ of PNA absorption remains constant and independent on the concentration. The optimum concentration was found to be $0.00112 \%$ in the final solution i.e. $2.0 \mathrm{ml} 0.014 \%(\mathrm{w} / \mathrm{v})$ is required in the final volume of $25 \mathrm{ml}$ of the reaction mixture.

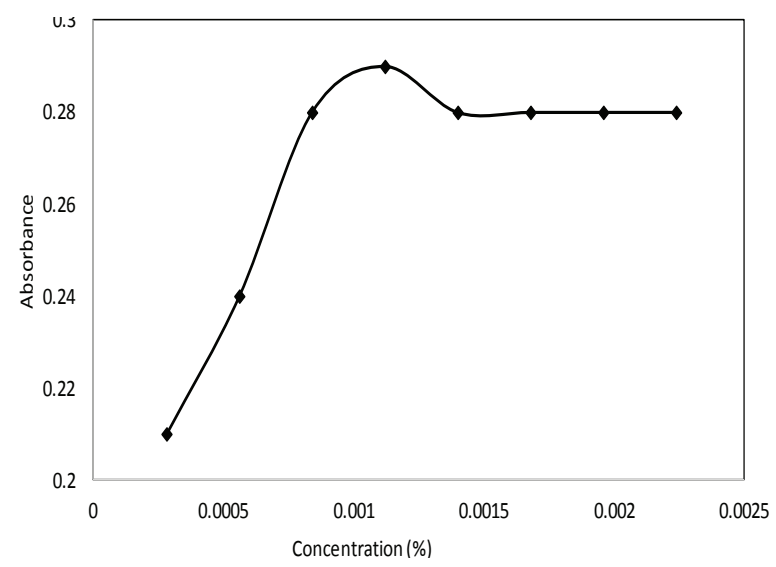

Fig. 2. Effect of PNA Concentration on Diasotization. Effect of Time Interval between the Addition of

\section{Aromatic Amine and Coupling Agent}

The effect of the time interval between the addition of p-nitroaniline and 1-naphthol was studied by adding these reagents at different time interval from 5 to 50 minutes. The plot of absorbance versus time for $25 \mathrm{ml}$ nitrite is shown in Fig. 3. It has been shown that absorbance of the azo dye was found to attain a maximum and the absorbance of the azo dye was found to attain a maximum and constant limiting value after 10 minutes and up to 15 minutes. This indicates that the diazotization process takes 10 minutes to be optimum and remains optimum up to 15 minutes. Hence, coupling agents must be added within 10-15 minutes after addition of diazotisable reagent. The coupling was found to be very fast since after addition of 1- naphthol, absorbance of the solutions remains practically constant up to 16 hour. This clearly indicates that the coupling occurs instantaneously and the azo dye formed is stable for at least 16 hour.

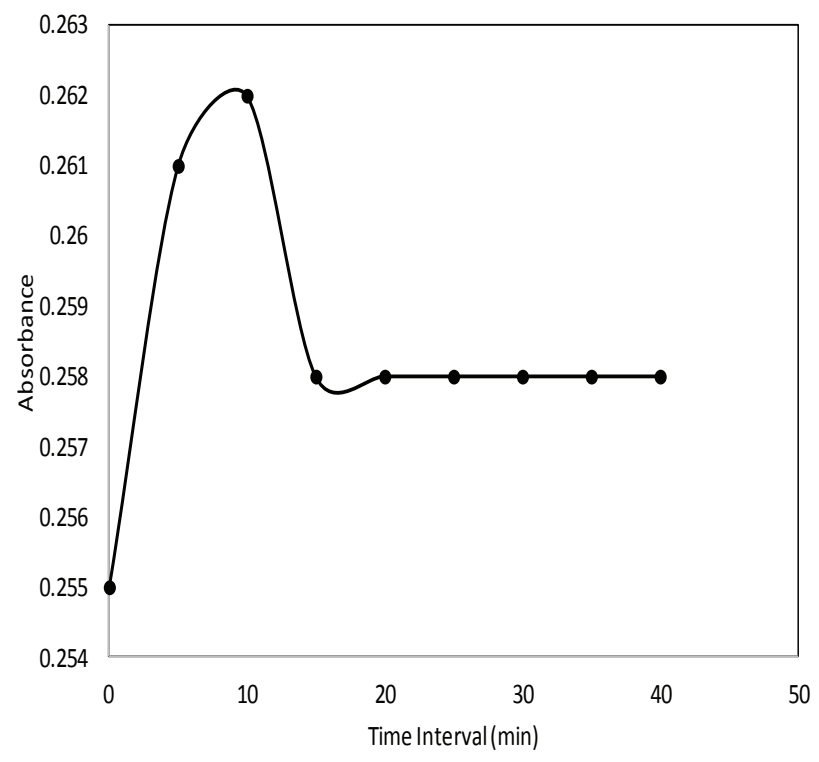

Fig. 3. Effect of Time Interval between the Addition of Aromatic amine and Coupling agent.

\section{Adherence to Beer-Lambert's Law and Sensitivity}

The adherence to the Beer- Lambert's law was tested by reacting aliquots of standard solution containing $1 \mu \mathrm{g}, 2 \mu \mathrm{g}, 3 \mu \mathrm{g}, 4 \mu \mathrm{g}, 5 \mu \mathrm{g}, 10 \mu \mathrm{g}, 15 \mu \mathrm{g}, 20 \mu \mathrm{g}$ and $25 \mu \mathrm{g}$ of nitrite in final volume of $25 \mathrm{ml}$ by the recommended procedure. The absorbance of the resulting azo dye is measured at $610 \mathrm{~nm}$. Fig. 4 shows the plot of absorbance against concentration of nitrite. The plot is found to be linear from the origin. From the plot it is clear that the proposed method obeys Beer-Lambert law from 0.035 to $0.123 \mathrm{ppm}$ of nitrite. 


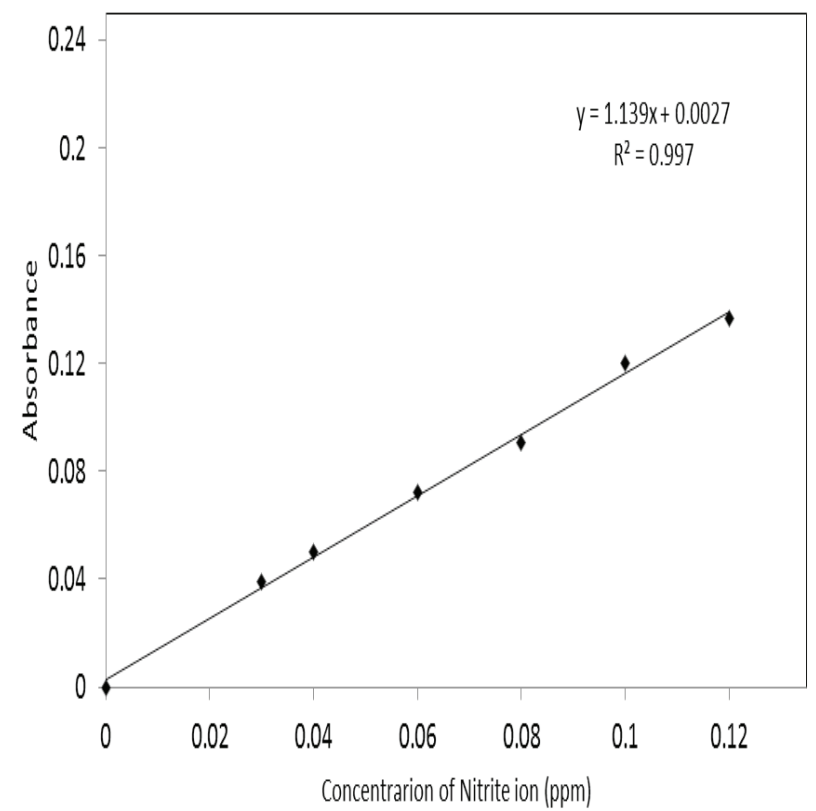

Fig. 4. The Plot of Absorbance vs. Concentration of Nitrite ion in ppm.

\section{Recommended Procedure for the Nitrite Determination in Water}

The determination of nitrite ion using p-nitroaniline acid as diazotisable amine and 1-naphthol as a coupling reagent is quite simple, accurate and highly reproducible. The highly sensitivity, simplicity rapidity, elimination of extractive steps and not requiring close adjustment of $\mathrm{pH}$ and temperature make the proposed method superior to the most of the Griess modifications. For the better results the following procedure is recommended for the determination of the nitrite in water samples are as follows: i) Take $15-20 \mathrm{ml}$ of water sample in $25 \mathrm{ml}$ volumetric flask. ii) Add $2 \mathrm{ml}$ of p-nitroaniline prepared in $0.05 \mathrm{M} \mathrm{HCl}$ and shake well then after keep the solution aside for the 15 minutes. iii) Add $1.5 \mathrm{ml}$ EDTA with 1.5 $\mathrm{ml} 0.1 \%$ of 1-naphthol make the solution up to the mark by adding distill water and measure the absorbance at $610 \mathrm{~nm}$. iv) Calculate the amount of nitrite in ppm from the calibration curve.

\section{Accuracy and Precision of the Method}

Under the optimum conditions, the proposed method was checked by performing three replicated determination of nitrite by taking and 1, 2, 3, 4, 5, 10, 15, 20, 25 and $30 \mu \mathrm{g}$ of nitrite in the final volume of $25 \mathrm{ml}$ by the recommended procedure. The percentage recovery was found to be range from $93-109 \%$ indicating the suitability of the method for determination of nitrite in water. The results of this analysis are shown in Table 1.
Table1. Accuracy and Precision of the Method

\begin{tabular}{|c|c|c|c|}
\hline $\begin{array}{c}\text { Nitrite } \\
\text { Taken}(\mu \mathrm{g})\end{array}$ & $\begin{array}{c}\text { Nitrite } \\
\text { found } \\
(\mu \mathrm{g}) \#\end{array}$ & $\begin{array}{c}\text { Mean } \\
\text { Recovery } \\
(\%)\end{array}$ & $\begin{array}{c}\text { Relative } \\
\text { standard } \\
\text { deviation }(\%)\end{array}$ \\
\hline 1 & $00.93 \pm 0.03$ & 093.0 & 3.2 \\
\hline 2 & $01.98 \pm 0.04$ & 099.0 & 2.0 \\
\hline 3 & $03.14 \pm 0.10$ & 104.0 & 3.2 \\
\hline 4 & $04.39 \pm 0.06$ & 109.0 & 1.4 \\
\hline 5 & $05.48 \pm 0.06$ & 109.0 & 1.1 \\
\hline 10 & $09.77 \pm 0.73$ & 098.0 & 7.4 \\
\hline 15 & $14.92 \pm 0.36$ & 099.5 & 2.4 \\
\hline 20 & $20.06 \pm 0.63$ & 100.0 & 3.1 \\
\hline 25 & $25.20 \pm 0.36$ & 100.8 & 1.4 \\
\hline 30 & $30.60 \pm 0.36$ & 102.0 & 1.2 \\
\hline
\end{tabular}

\#Average of three determinations \pm SD

\section{Proposed Reaction Mechanism}

The reaction is believed to occur in two steps. In the first step p-nitroaniline reacts with nitrite the presence of acid to form the diazonium cation. In the second step, the diazonium cation subsequently couples with alkaline solution of 1-naphthol to produce the violet colour azo dye. The azo dye has intense color which has absorption maximum in visible region.

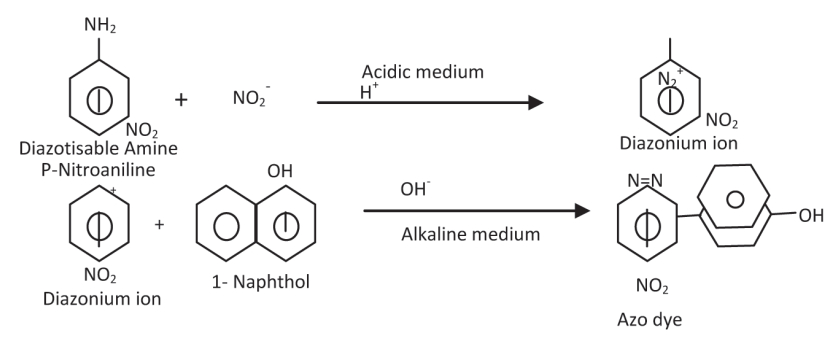

\section{Effect of Foreign Ions}

The effects of foreign ions that often accompany nitrite are examined by carrying out the determination of $20 \mu \mathrm{g} /$ $\mathrm{ml}$ of Nitrite in $25 \mathrm{ml}$ volumetric flask; $2 \mathrm{ml}$ of $20 \mu \mathrm{g} / \mathrm{ml}$ Sodium nitrite solution was taken in $25 \mathrm{ml}$ volumetric flask. Then $2 \mathrm{ml}$ of $1 \times 10^{-3} \mathrm{M}$ PNA solution was added followed by the addition of $3 \mathrm{ml}$ of $0.05 \mathrm{M} \mathrm{HCl}$ solution. Then the solution was thoroughly shaken and kept aside for 10 minutes to allow the diazotization reaction. Then 1 $\mathrm{ml}$ of $10 \%(\mathrm{w} / \mathrm{v})$ EDTA was added followed by addition of $1.5 \mathrm{ml}$ of $0.1 \%(\mathrm{w} / \mathrm{v}) 1$-naphthol and shaken for one minute. After that the different foreign ion weight which are reported below are mixed from different compound. The volume was made up to the mark by the addition of water. The effects of foreign ions that often accompany nitrite are examined by carrying out the determination of $20.0 \mu \mathrm{g}$ of nitrite in $25 \mathrm{ml}$ volumetric flask with the foreign ions following the recommended procedure. The 
foreign ions tested are $\mathrm{Na}^{+}, \mathrm{K}^{+}, \mathrm{NH}_{4}^{+}, \mathrm{Ca}^{++}, \mathrm{Mg}^{++}, \mathrm{Cu}^{++}$, $\mathrm{Cl}^{-}, \mathrm{NO}_{3}^{-}, \mathrm{HCO}_{3}^{-}, \mathrm{CO}_{3}^{--}, \mathrm{SO}_{4}^{--}, \mathrm{PO}_{4}^{--}, \mathrm{Fe}^{++}$. The results of this analysis are shown in Table 2. It is apparent that interference due to most of the foreign ions is negligibly small and the method seems to be selective for nitrite. But, however $\mathrm{Cu}^{++}$and $\mathrm{Fe}^{++}$ions interfere seriously while $\mathrm{Mg}^{++}$and $\mathrm{PO}_{4}^{---}$interfere by causing turbidity to the solution.

Table 2. Effect of Foreign Ions on Absorbance of $10 \mu \mathrm{g} / \mathrm{ml}$ of Nitrite Treated by Recommended Procedure

\begin{tabular}{|l|c|c|c|c|}
\hline $\begin{array}{l}\text { Foreign } \\
\text { ions }\end{array}$ & $\begin{array}{c}\text { Amount } \\
\text { added(mg) }\end{array}$ & $\begin{array}{c}\text { Ratio of } \\
\text { diverse } \\
\text { ion/nitrite, } \\
\mathrm{wt} / \mathrm{wt}\end{array}$ & Absorbance & $\begin{array}{c}\text { Nitrite } \\
\text { found } \\
(\mu \mathrm{g})\end{array}$ \\
\hline Sodium & 92.00 & 4600 & 0.956 & 21.00 \\
\hline Potassium & 39.00 & 1950 & 0.952 & 20.90 \\
\hline Ammonium & 18.00 & 900 & 0.957 & 21.01 \\
\hline Calcium & 48.00 & 2000 & 0.962 & 21.12 \\
\hline Magnesium & 02.40 & 120 & 0.911 & 20.00 \\
\hline Copper & 02.54 & 127 & 0.820 & 18.00 \\
\hline
\end{tabular}

\begin{tabular}{|l|l|l|l|l|}
\hline Chloride & 71.00 & 3550 & 0.956 & 21.00 \\
\hline Nitrate & 62.00 & 3100 & 1.002 & 22.00 \\
\hline Bicarbonate & 61.00 & 3050 & 1.006 & 22.10 \\
\hline Carbonate & 60.00 & 3000 & 1.007 & 22.12 \\
\hline Sulphate & 19.20 & 0960 & 0.956 & 21.00 \\
\hline Phosphate & 96.00 & 4800 & 0.902 & 19.80 \\
\hline Iron & 55.80 & 2790 & 0.775 & 17.00 \\
\hline
\end{tabular}

\section{Analysis of Water Samples}

To determine the concentration of nitrite in water samples at first water sample was collected from different source like tap water, ponds, tube wells, wells, rivers and lakes etc. When we collected water from different sources we should be used clean and dry water pots. If we were collected water from river we reach that water which have a motion, and if we cannot test water in 24 hours we can use preservative like as $\mathrm{HgCl}_{2}$ the proposed method have been applied for the determination of nitrite in water samples by taking the $15 \mathrm{ml}$ of water samples in final volume of $25 \mathrm{ml}$ according to recommended procedure. The concentration of nitrite ( $\mathrm{ppm}$ ) obtained from water samples from various locations are shown in Fig. 5.

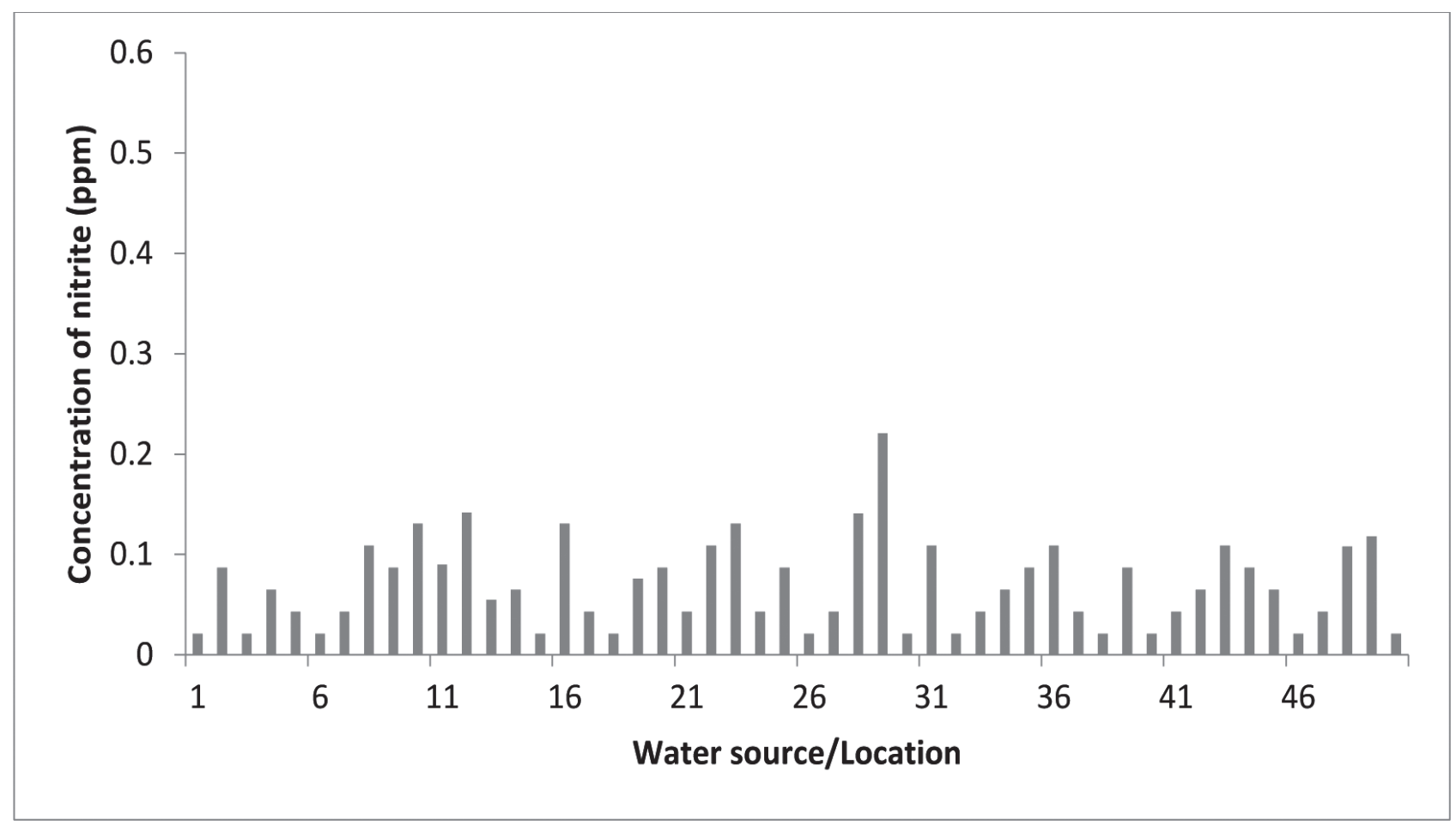

Fig. 5. The Plot of Concentration of Nitrite vs. Water from different sources and locations.

Comparison of the Proposed Method with Some Reported Method

The present method is sensitive, selective and economical in which PNA reagent in the presence of acid reacts with nitrite to form diazonium ion which on coupling with suitable coupling agent 1- naphthol gives violet colored azo dye. The comparison and the application of the method reflect that the developed is appropriate for the determination of nitrite in water. The result of the comparison is shown in Table 3. 
Table 3. Comparison of the Proposed Method with some Reported Methods

\begin{tabular}{|c|c|c|c|c|c|}
\hline Method & Reagent & $\begin{array}{c}\lambda_{\max } \\
(\mathrm{nm})\end{array}$ & $\begin{array}{c}\text { Molar Absorptivity } \\
\left.\text { (litmol }^{-1} \mathbf{c m}^{-1}\right)\end{array}$ & $\begin{array}{c}\text { Determination } \\
\text { range (ppm) }\end{array}$ & Reference \\
\hline 1. & p- Nitroaniline + Frusemide & 680 & $3.314 \times 10^{3}$ & $0.4-2.0$ & 6 \\
\hline 2. & p-Nitroaniline + Ethoxyethylenemaleic ester & 439 & $1.21 \times 10^{4}$ & $0.5-16.0$ & 7 \\
\hline 3. & Barbituric acid & 310 & $1.53 \times 10^{4}$ & $0.00-3.22$ & 8 \\
\hline 4. & 4- Aminophenylacetic acid + 1- Naphthol & 490 & $2.70 \times 10^{4}$ & $0.04-1.6$ & 9 \\
\hline 5. & p-Nitroaniline + Diphenylamine & 500 & $1.425 \times 10^{4}$ & $0.05-0.80$ & 10 \\
\hline 6. & 4- Aminosalicylic acid + & 520 & $1.47 \times 10^{4}$ & $0.1-3.0$ & 11 \\
\hline 7. & Sulfanilic acid + 1-Naphthylamine & 520 & $3.30 \times 10^{4}$ & $1.4-35$ & 12 \\
\hline 8. & p-Aminobenzoic acid + 8-Hydroxyquinoline & 499 & $3.20 \times 10^{4}$ & $0.1-1.5$ & 13 \\
\hline 9. & p-Nitroaniline+ 1 - Naphthol [proposed method] & 610 & $5.240 \times 10^{4}$ & $0.035-0.123$ & \\
\hline
\end{tabular}

\section{CONCLUSIONS}

The purposed method is simple, sensitive and highly reproducible method for the spectrophotometric determination of trace amount of nitrite present in water sample. The proposed method involves diazotization of the p-nitroaniline followed by coupling with 1-naphthol to give a stable violet coloured azo dye. The optimized amounts of reagents were found to be $2.0 \mathrm{ml} 0.014 \%$ p-nitroaniline, $2.5 \mathrm{ml} \mathrm{HCl}, 1.5 \mathrm{ml} 10 \%$ EDTA and 1.5 $\mathrm{ml} 0.1 \%$ 1-naphthol. This method follows LambertBeer's law over range $0.035-0.123 \mu \mathrm{g} / \mathrm{ml}$ of nitrite. The percentage recovery was found to range from 93$109 \%$. The correlation coefficient, molar absorptivity and Sandell's sensitivity of the method were found to be $0.997,5.24 \times 10^{4}$ lit.mol ${ }^{-1} \mathrm{~cm}^{-1}$ and $8.77 \times 10^{-4} \mu \mathrm{gcm}^{-2}$ respectively. The validity of the method is also assessed by investigating the effect of common foreign ions. This method should be tested to the soil samples for further study.

\section{ACKNOWLEDGEMENTS}

The authors are thankful to M.Sc. Coordinator and Head of the Department, Department of Chemistry, Tri-Chandra Multiple Campus, Tribhuvan University, Ghantaghar and Kathmandu for providing the available research facilities to conduct this research work.

\section{REFERENCES}

Calabrese, E. J. 1963. Pollutants and High Risk Groups. Wiley Interscience, New York, U.S.A., 917 p.

Standard Method for the Examination of Water Sewage and Industrial Waste (SMEWSIW). 1976. America Public Health Association(APHA), Inc. Washington, $406 \mathrm{p}$.

Chaurasis, A. and Verma, K. K. 1994. Flow injection spectrophotometric determination of nitrite. Talanta 41: 1275-1279.
Butt, S. B., Riaz, M. and Iqbal, M. Z. 2001. Simultaneous determination of nitrite and nitrate by normal phase ion-pair liquid chromatography. Talanta 55(4) : 789-797.

Siu, D. C. and Henshall , A. 1998. Ion chromatographic determination of nitrite and nitrate in meat products. J. Chromatogr. 804: 157-160.

Veena, K. and Narayana, B. 2009. Spectrophotometric determination of nitrite using new coupling agents. Indian Journal Chemical Talanta 16: 89-93.

Cherian, T. and Narayana, B. 2006. A new system for the spectrophotometric determination of trace amounts of nitrite in environmental samples. $J$. Braz. Chem. Soc. 17(3): 577-581.

Cotton, F. A. and Wilkinson, G. 1988. Advanced Inorganic Chemistry, $5^{\text {th }}$ ed., John Wiley and Sons Inc.

Pradhananga, R. R., Khadka, D. B. and Sherestha, N. K. 1992. Spectrophotometric determination of trace amount of nitrite in water with 4-aminophenylacetic acid and 1-naphthol, J. Nepal Chem. Soc. 11: 3643.

Afkhami, A., Masahi, S. and Bahram, M. 2004. Spectrophotometric determination of nitrite based on its reaction with p-nitroaniline in the presence of diphenylamine in micellar media. Bull. Korean Chem. Soc. 25: 1009-1011.

Flamerz, S. and Bashir, W. A. 1981. Spectrophotometric determination of nitrite in waters. Analyst 106: 243-247.

Saltzman, B. E. 1954. Colorimetric microdetermination nitrogen dioxide in atmosphere. Anal. Chem. 26(12): 1949-1955.

Bashir, W. A. and Flamerz, S. 1981. Photometric determination of nitrite. Talanta 28(9): 697-699. 